\title{
APOIO DA TECNOLOGIA DA INFORMAÇÃO E COMUNICAÇÃO COMO ESTRATÉGIA COMPETITIVA NA GESTÃO DA CADEIA DE SUPRIMENTOS
}

\section{INFORMATION AND COMMUNICATION TECHNOLOGY SUPPORTING COMPETITIVE STRATEGY IN SUPPLY CHAIN MANAGEMENT}

\author{
Adilson Torres ${ }^{1}$; Clóvis Luis Padoze ${ }^{2}$; Silvio Roberto Ignácio Pires ${ }^{3}$ \\ ${ }^{1}$ Universidade Metodista de Piracicaba - UNIMEP - Piracicaba - Brasil \\ adilson_torres@oi.com.br \\ ${ }^{2}$ Universidade Metodista de Piracicaba - UNIMEP - Piracicaba - Brasil \\ cpadoveze@yahoo.com.br \\ ${ }^{3}$ Universidade Metodista de Piracicaba - UNIMEP - Piracicaba - Brasil \\ sripires@unimep.br
}

\section{Resumo}

A competição entre as empresas está cada vez mais acirrada.Segundo especialistas o campo atual desta disputa é entre cadeias de suprimentos, e não apenas entre unidades isoladas. A informação no ambiente empresarial tem evoluído muito nas últimas décadas, por meio da contribuição da tecnologia da informação e comunicação (TIC), que apresenta constantes inovações ao longo do tempo. Todavia para que haja uma real vantagem competitiva, é fundamental que os parceiros dessas cadeias consigam manter troca de informações estratégicas, para a gestão do conhecimento e monitoramento das operações. Para suportar essa necessidade, o apoio da tecnologia da informação e comunicação (TIC) é essencial. Esse trabalho apresenta-se no formato de um ensaio teórico. A abordagem metodológica utilizada neste documento é analítico-conceitual, portanto teórico, com objetivo exploratório. A metodologia empregada na sua construção e organização calca-se numa pesquisa bibliográfica, ou seja, na síntese da literatura existente, num caráter preponderantemente qualitativo, e com a análise crítica dos problemas levantados e a sua discussão.

Palavras-chave: tecnologia da informação e comunicação; gestão da cadeia de suprimentos; estratégia competitiva.

\section{Introdução}

Entre as diversas vantagens competitivas que as empresas necessitam na atualidade, tem-se a tecnologia da informação e comunicação. Segundo Padoveze (2006), a necessidade de informação das pessoas advém com o surgimento da civilização, sedentarização e a descoberta da capacidade de armazenar bens e da necessidade de controle.

Existem evidências de controles com características contábeis nas civilizações dos sumérios, babilônios, assírios, egípcios, hebreus, gregos etc. 
Muitos conceitos, aplicações e sistemas se desenvolveram rapidamente depois da Segunda Grande Guerra Mundial. Segundo Oliveira (2000), surgiram os seguintes termos: sistemas de defesa, sistemas hidráulicos, sistemas econômicos etc.

Um sistema é uma rede de componentes interdependentes que trabalham em conjunto para tentar realizar o objetivo do sistema. Um sistema deve ter um objetivo (OLIVEIRA, 200, p. 149).

Segundo Padoveze (2009), é preciso distinguir os termos: informação, dado e comunicação. Dado é o registro puro, ainda não processado, analisado e interpretado; informação é o dado processado e armazenado de forma estruturada, e - comunicação ou conhecimento é a transmissão da informação e compreensão ao usuário. A Figura 1 mostra o fluxo da utilização de dados, seu processamento e transformação em informações, e a utilização das informações para o processo de tomada de decisão.

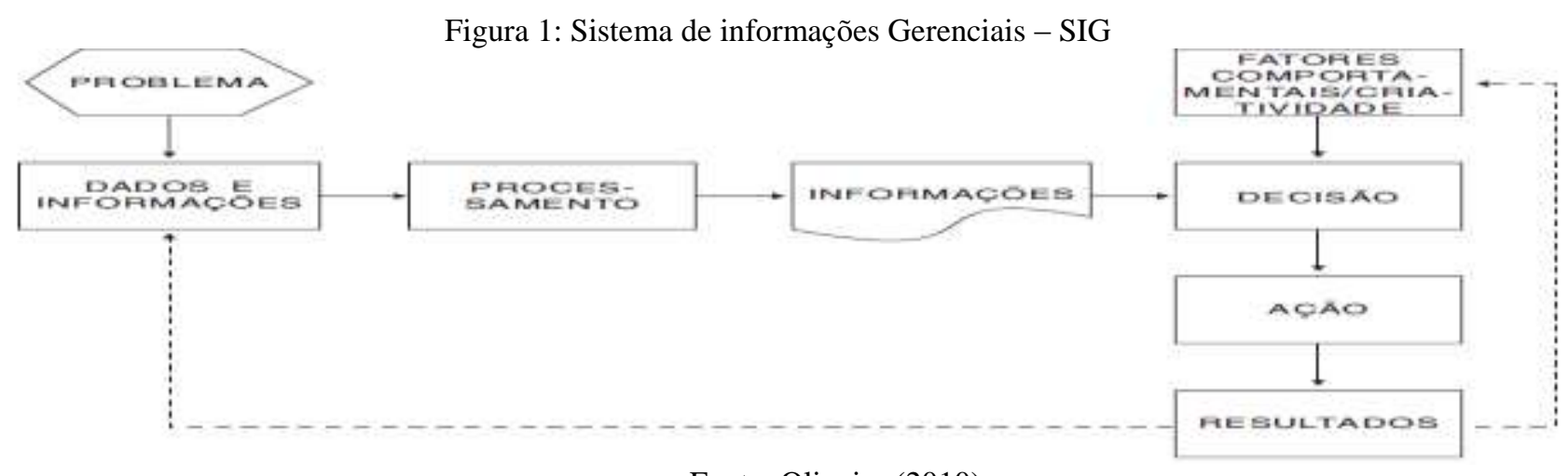

Fonte: Oliveira (2010)

O conhecimento gerado agrega valor ao dado, para que este possa gerar suporte na tomada de decisão, e conseqüentemente gerar uma ação, segundo Leme Filho (2004). "Nos últimos 50 anos de aplicação prática dos recursos de tecnologia da informação (TI) no ambiente empresarial foram repletos de inovações. Houve alterações significativas, que mudaram não apenas a tecnologia, mas o próprio ambiente empresarial" (SORDI, 2003, p. 21).

O conceito de Tecnologia da Informação (TI) é mais abrangente do que os de processamento de dados, sistemas de informação, engenharia de software, informática ou conjunto de hardware e software, pois também envolve aspectos humanos, administrativos e organizacionais (LAURINDO, Fernando J. Barbim, 2002 apud PADOVEZE, 2009, p. 29).

De acordo com Padoveze (2009) a TI já faz parte do planejamento estratégico nas organizações, e neste contexto não se limita mais a informações e controles internos. Deve alcançar, também, toda a cadeia: fornecedores, clientes etc. A TI, portanto, é um fator chave para a competitividade destas cadeias. O uso da TI nas empresas propicia vantagens, conforme relatadas a seguir: 
As empresas ao implantarem os Sistemas de Informações (SI), podem obter benefícios tais como: conceder suporte à tomada de decisão profícua; adicionar valor agregado aos bens e serviços por elas ofertados; ofertar produtos de qualidade superior à de suas concorrentes; obter oportunidades de negócios e aumento da rentabilidade, ter mais segurança nas informações, menos erros, mais precisão; aperfeiçoar os sistemas, com eficiência, eficácia e efetividade, produtividade; reduzir carga de trabalho; reduzir custos e desperdícios; controlar as operações etc (Rezende, 2000 apud GOMES, 2004, p. 283).

Segundo Gomes (2004), existem fatores que dificultam a implantação da TI, como por exemplo a resistência a inovação e as mudanças, a falta da necessidade de vantagem competitiva, o desconhecimento dos benefícios da TI, os problemas de comunicação dentro da empresa, a falta de medidas de medição de desempenho da TI.

Existem outros fatores apontados pelo Leme Filho (2004), relativo à qualidade da informação, a cultura dos usuários, a padronização de conceitos de informações, a forma de visualização das informações. Um fator que contribui neste cenário parece ser a falta de conhecimentos dos dirigentes, apesar da comprovada necessidade da TI:

Os executivos atuais reconhecem que a TI é um componente fundamental para o sucesso de seus negócios. Muitos deles têm visão limitada ou mesmo não compreendem como a TI pode auxiliá-los, têm dificuldades para identificar os processos mais apropriados para aplicação da TI, ou seja, aqueles que darão o melhor retorno à organização (SORDI, 2003, p. 22).

Um grande impacto gerado pela TI, segundo Sordi (2003) foi à redução nos níveis hierárquicos, onde a maioria dos trabalhos desempenhados pela média gerência (nível tático) e passou para os sistemas de informações, ou seja, consolidar e preparar dados, direcionar decisões.

As principais áreas funcionais da empresa se adequaram a TI: marketing, administração financeira, produção, recursos humanos, gestão empresarial, administração de materiais, etc.

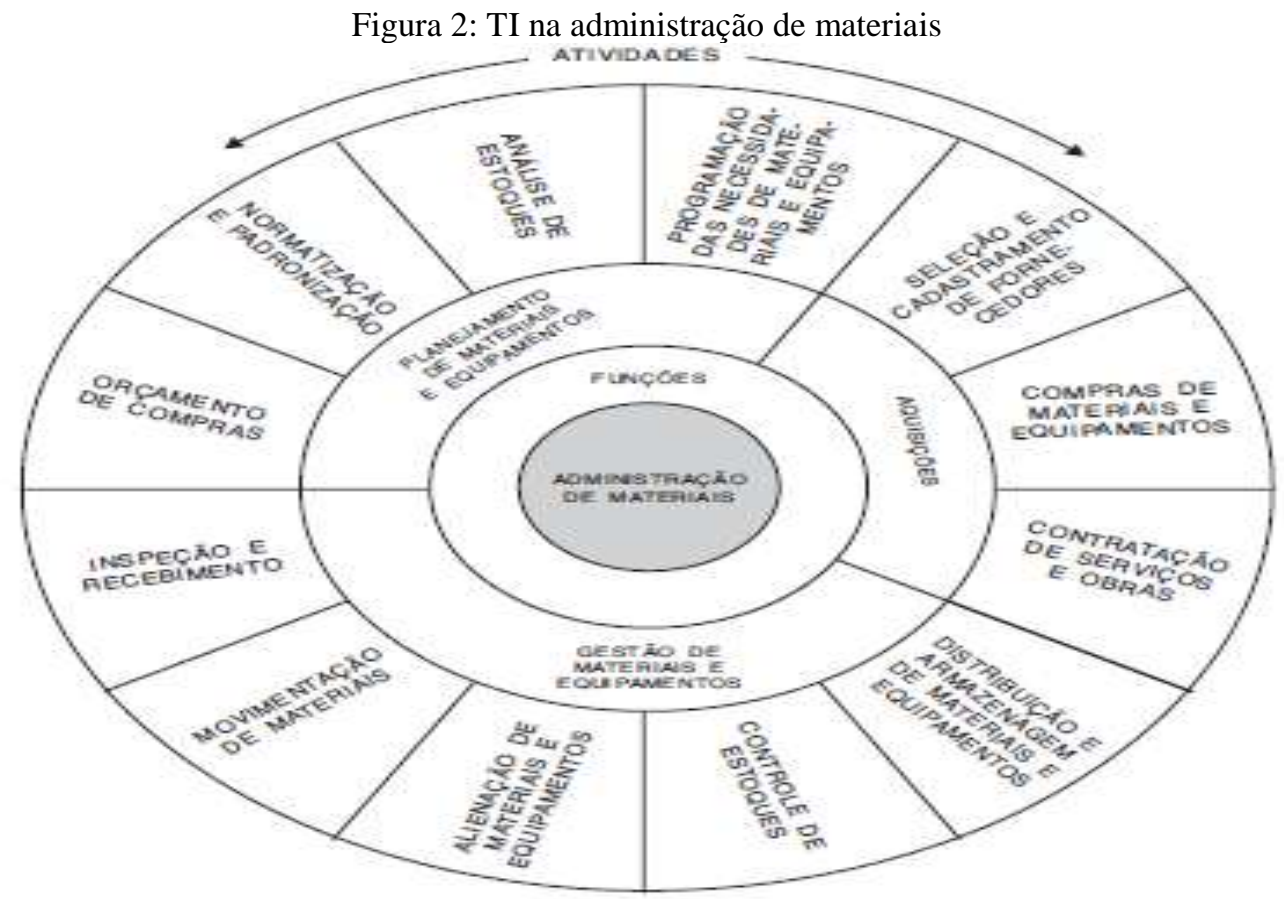

Fonte: Oliveira (2010) 
Segundo ANGELONI (2008) os fatores determinantes da competitividade são: os empresariais (internos, que podem ser controlados), os estruturais (mercado, que podem ser parcialmente controlados) e os sistêmicos (não há forma de controlar: a política, aeconomia, a legislação, o social, etc.):

Para esses autores, na definição da estratégia, a informação está intensamente envolvida e deve ser tratada com a mesma seriedade com que são tratados os demais recursos estratégicos, considerando-se que uma definição de estratégia eficiente exige informação precisa, em tempo hábil e no volume necessário (ANGELONI, 2008, p. 113).

Muitas organizações que fazem investimentos e uso da TI, mas segundo Angeloni (2008), não possuem uma definição clara do que realmente esperam dessas tecnologias e a sua real contribuição para o seu negócio.

Figura 3: Necessidade de informação X crescimento da empresa

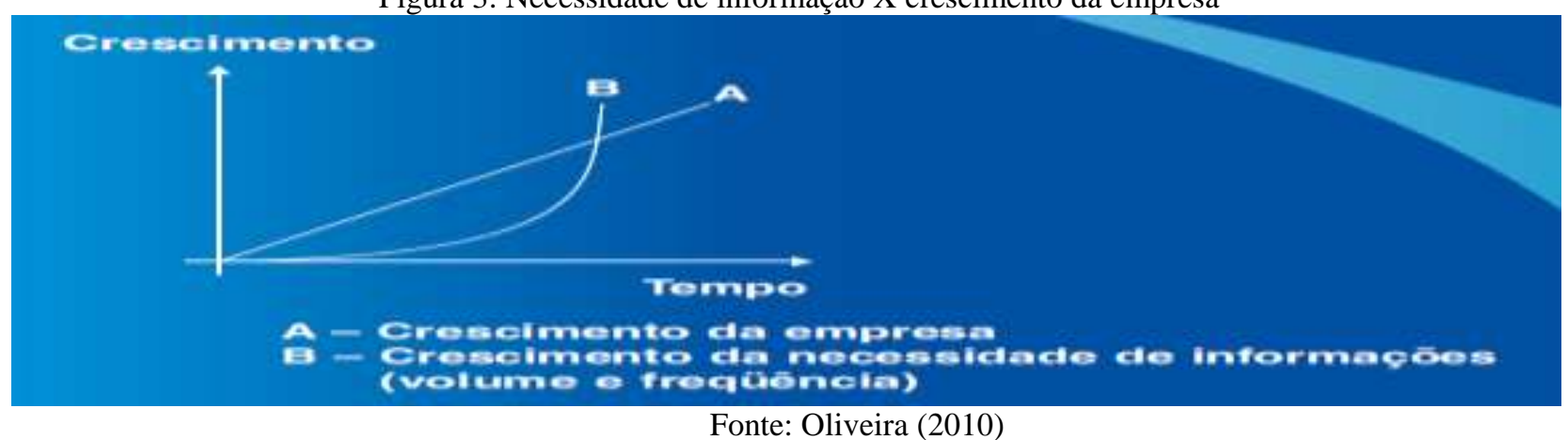

Todavia apesar da comprovada utilidade da TI na gestão das cadeias de suprimentos, existem ainda várias críticas com relação a sua utilização prática. Conforme estudo elaborado por Maçada (2007), alguns dirigentes ainda demonstram desconhecimento em relação aos impactos no desempenho, falta de medidas não financeiras, e usam várias medidas voltadas ao retorno de investimentos e relativas a faturamento, limitando a análise, e isso provocam a subutilização ou utilização inadequada da TI em muitas empresas.

Dentro da empresa a solução para os processos de back office(sistemas operacionais), ficou consagrada com a utilização dos Sistemas Integrados de Gestão ou Enterprise Resource Planning (ERP) amplamente difundidos a partir da década de 1990, segundo Sordi (2003). Padoveze (2009, p. 45) afirma que "mais recentemente, um avanço neste tipo de informação, com inclusão da Internet e seu acoplamento com os sistemas integrados de gestão, tem denominado esses sistemas de Business Intelligence (BI) ou Sistemas de Inteligência dos Negócios”. A figura 4 traz uma representação desse sistema: 
Figura 4: Sistema integrado de informações

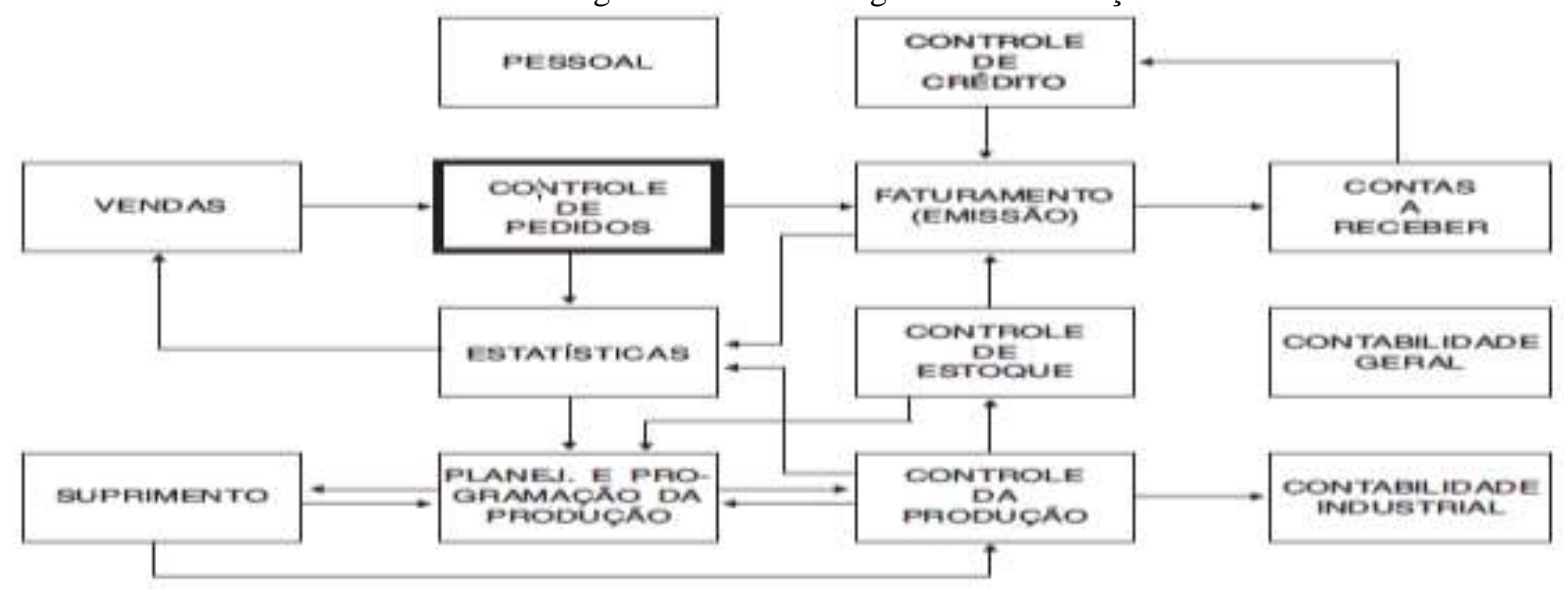

Fonte: Oliveira (2010)

Segundo Pires (2010), o desenvolvimento da TIC - tecnologia da informação e comunicação vem se desenvolvendo com grande força a partir de 1990 até os dias atuais e a internet está se tornando algo revolucionário.

Os impactos na gestão da produção, com o desenvolvimento da TIC, segundo Pires (2010), com a evolução de programas e de computadores, iniciando no final dos anos 1960 com o Material Resource Planning (MRP), até sistemas abrangentes de ERP, tem sido enormes.

Por sua vez, o papel transformador da Internet como rede de comunicação global também dispensa maiores comentários [...]. Em poucos anos a comunicação tornou-se on-line, global, e o volume de informações disponíveis tornou-se uma grande marca dos dias atuais. Bem, da natural e já notória expansão da TIC e da Internet como instrumento a serviço da gestão das cadeias de suprimento [...] (PIRES, 2010, p. 14-15).

Com o crescimento e popularização da Internet, a gestão da TI nas empresas evoluiu drasticamente, complementada com novas necessidades, produtos e equipamentos de informática, e também por meio de novas tecnologias de programação e comunicação.

A tendência da globalização da economia, segundo Padoveze (2009), impõe a necessidade da harmonização e padronização de conceitos, princípios e práticas em toda a área do conhecimento. Isto pode gerar convergência de procedimentos e informatização de dados entre as empresas integrantes de uma cadeia de suprimentos.

Como por exemplo: os padrões contábeis americanos (USGAAP - Generally Accepted Accounting Principles), editado pela FASB - Financial Accounting Standards e atualmente pela adoção das normas internacionais de contabilidade emandas do IASC - International Accounting Standards Committee, órgão atualmente denominado de IASB - International Accounting Standards Board, sendo divulgadas até 2001 as normas denominadas de IAS - International Accounting Standards ainda em vigor, e a partir desta data ser denominadas de IFRS - International Financial Reporting Standardas. Com isto há tendência para a convergência mundial do padrão contábil utilizado entre as empresas, idependente de sua localização geográfica, segundo Carvalho e 
Lemes (2010).

A convergência contábil deverá exigir futuramente uma linguagem de programação compatível com esta convergência, para importação, integração e consolidação de dados, em uma base unificada, com objetivo de redução e racionalização dos custos administrativos na consolidação contábil, objetivo principal da adoção das normas internacionais de contabilidade, que já foi adotada por diversos paises, inclusive o Brasil pelas Leis no. 11.638/2007 e 11.941/2009 e criação do CPC - Comitê de Pronunciamentos Contábeis, a partir de norma específica do CFC Conselho Federal de Contábilidade pela Resolução CFC no. 1.055/2005.

Segundo Pires (2010), surgiram grandes avanços na TIC: as fibras óticas, a comunicação sem fio (wireless), a evolução da digitação de dados, para a leitura de códigos de barras, a radiofreqüência, o armazenamento de dados (data warehousing), a mineração de dados (data mining), a biometria e as ferramentas de acesso a base de dados OLAP (On-line Analytical Processing).

No Brasil, tem-se a contribuição do SPED (Sistema Público de Escrituração Digital), elaborado pela Receita Federal em convênio com os Estados e vários outros órgãos federais, que instituiu a utilização de transmissão de dados no formato XML (Extensible Mark-up Language), para utilização na emissão de NF-e (Nota Fiscal Eletrônica), ECD (Escrituração Contábil Digital) e EFD (Escrituração Fiscal Digital), como parte do PAC (Programa de Aceleração do Crescimento).

O resultado deste fenômeno, de acordo com Padoveze (2009), será a utilização da linguagem XBRL - Extensible Business Reporting Language, porque isto simplifica o processo de intercâmbio de informações para um formato universal, e pode gerar em seguida uma informação que poderá ser reutilizada em quaisquer formatos de linguagem computacional.

A figura 5 demonstra a integração dos fluxos de informações entre todos os elos de uma cadeia de suprimentos, viabilizada pela utilização da NF-e, o uso da internet e da linguagem aberta no formato XML.

\section{Figura 5: Fluxo NF-E}

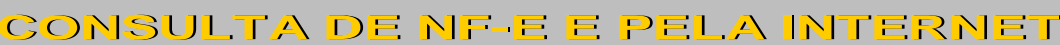

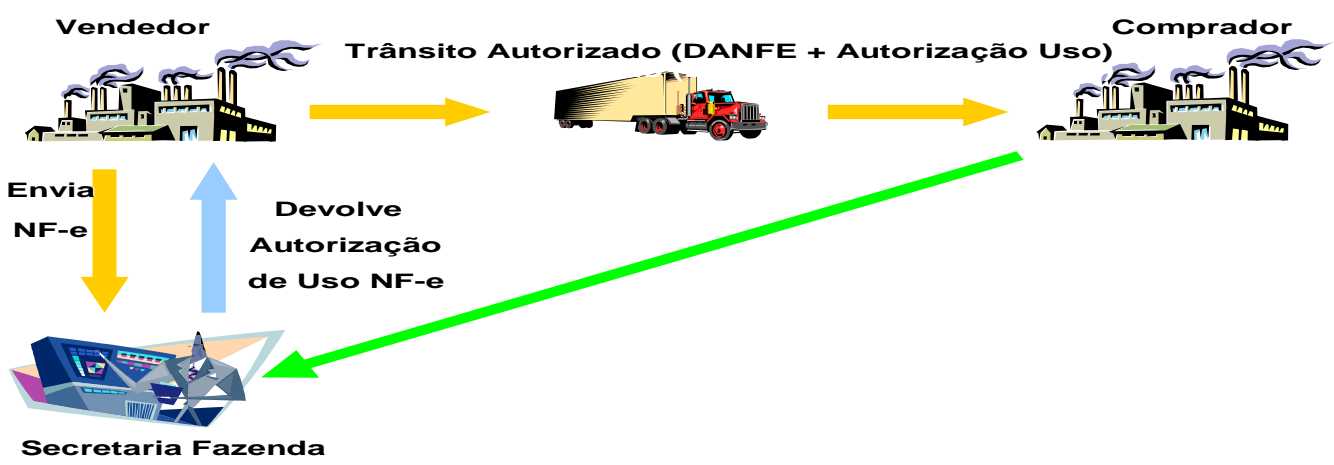

Fonte: Ministério da Fazenda (2010) 
Esta iniciativa do governo tratará vários impactos positivos, no desenvolvimento da TIC na SCM (Supply Chain Managment):

Outro facilitador tecnológico do SCM através da Internet é a utilização do formato XML (Extensible Mark-up Language) para troca de dados, um grande facilitador se comparado à tecnologia de Electronic Data Interchange (EDI) empregada no SCM tradicional. O XML é um formato flexível para entrega de dados via Internet que ocorre independente da plataforma tecnológica utilizada pelas empresas do supply chain (SORDI, 2003, p. 65).

O objetivo deste trabalho é demonstrar como a tecnologia da informação e comunicação, pode servir de instrumento a tomada de decisão, explorar a gestão da cadeia de suprimentos e logística empresarial, suas particularidades, levantamento das principais ferramentas existentes, e sua aplicabilidade, analisar a contribuição para uma vantagem competitiva frente às estratégias empresariais existentes.

\section{Revisão bibliográfica}

\subsection{Gestão da cadeia de suprimentos, logística e sistemas produtivos}

Segundo Pires (2010), a Gestão da Cadeia de Suprimentos (SCM - Supply Chain Management), desde meados de 1990, ocupa lugar de destaque na gestão industrial, principalmente naqueles segmentos de indústria com maior competição.

Também, segundo Pires (2010), a gestão da cadeia de suprimentos SCM (Supply Chain Management) envolve processos entre fornecedores-clientes desde a matéria-prima até o consumidor final, gerenciando funções dentro e fora da empresa para garantir valor aos clientes.

A logística oriunda da área militar, segundo Pires (2010), evoluiu da prática de expedição de produtos e serviços de transportadoras para agregadora de valor ao cliente, através da análise cuidadosa do produto ao longo da cadeia de valor, destaca-se a necessidade de competitividade no processo de entregas, como vantagem competitiva.

Quanto ao processo produtivo, destacam-se as forma de produção: para estoque e por encomendas, e o processo de customização em massa, que exercem forte influência na forma de estrutura do processo estratégico das empresas, de acordo com a sua forma de atuação, bem como a variabilidade de materiais e produtos finais.

A gestão da cadeia de suprimentos, segundo Pires (2010), envolve processos entre fornecedores-clientes desde a matéria-prima até o consumidor final, por meio da gestão de funções dentro e fora da empresa para garantir valor aos clientes. 


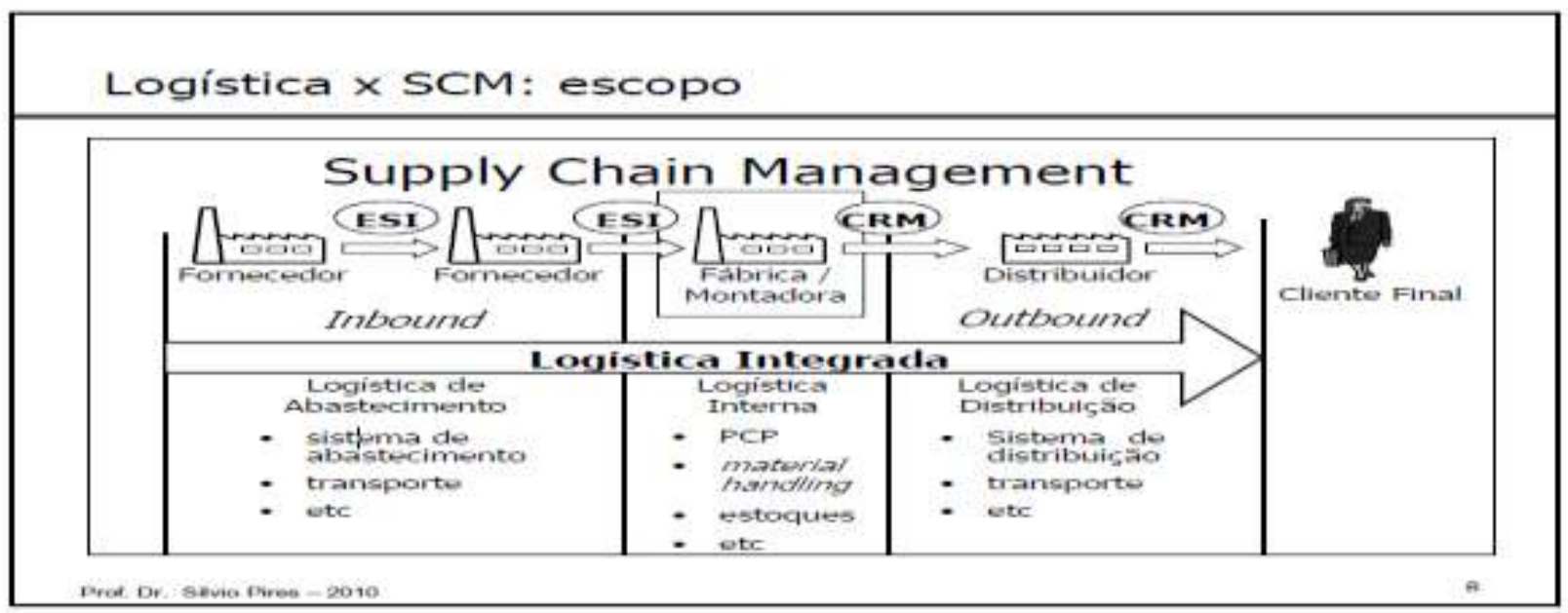

Fonte: Pires (2010)

Segundo Pires (2010), a SCM pode ser vista como uma expansão: da Gestão da Produção (production management), da Logística (logistics), do Marketing e de Compras (purchasing), é uma área multifuncional, que possui em seu espoco três grandes eixos: os processos de negócios, as tecnologias e os sistemas, a organização e as pessoas. Essas parcerias visam na gestão colaborativa entre todos os membros participantes de uma cadeia de suprimentos.

A logística é o processo de gerenciar estrategicamente a aquisição, a movimentação e o armazenamento de materiais, peças e produtos acabados (e os fluxos de informação correlatos) por meio da organização e dos seus canais de marketing, de modo a poder maximizar as lucratividades presentes e futuras com o atendimento dos pedidos a baixo custo (GOMES, 2004, p. 1).

Segundo Gomes (2004) a logística tem como atividade básica a preocupação com: transporte, manutenção de estoques e processamento de pedidos. De acordo com Gomes (2004) com o objetivo de agregar valor e não custo ao produto, é necessário manter um fluxo mais eficiente para evitar grandes estoques, por meio da adoção de estratégia e conceitos de gestão como, por exemplo, a demanda puxada e a empurrada, o Just-in-time, o kanban, a curva ABC etc.

Com relação aos aspectos gerais relativos a transporte, tem-se o seguinte comportamento: "No Brasil, a maior parte dos fluxos de carga (70\%) é transportada pelo modo rodoviário, (15\%), pelo ferroviário e (15\%) pelo marítimo e cabotagem e pelo aero, considerando-se o transporte interno" (GOMES, 2004, p. 67).

De acordo com Gomes (2004), o custo do transporte no Brasil representa a maior parcela dos custos logísticos, na maioria das empresas.

Embora seja um conceito em evolução, cuja utilização ainda se restringe a um conjunto de empresas mais avançadas, a SCM já está na agenda da maioria dos gerentes das grandes empresas internacionais. Artigos na impressa especializada, como a Fortune, estão anunciando a SCM como a nova fonte de vantagens competitivas (FLEURY, 2000, p. 43).

Segundo Fleury (2000) entre os processos de negócios chaves para o sucesso da SCM, são 
os seguintes: os relacionamento com os clientes, os serviços aos clientes, a administração da demanda, o atendimento de pedidos, a administração do fluxo de produção, compras / suprimentos e o desenvolvimento de novos produtos.

\subsection{Sistemas de informação}

Sistemas de informações envolvem vários recursos, segundo O’brien (2004): humanos, hardware, software, dados e rede, que se relacionam com atividades de entrada de dados, transformação de dados, saída de informação, qualidade da informação, armazenamento de dados e controle de desempenho do sistema.

O papel estratégico dos sistemas de informação envolve a utilização de tecnologia da informação para desenvolver produtos, serviços e capacidades que confiram a uma empresa vantagens estratégicas sobre as forças competitivas que ela enfrenta no mercado mundial. Esse papel gera sistemas de informação estratégica, que apóiam ou moldam a posição e estratégias competitivas de uma empresa (O’BRIEN, 2004, p. 41).

Segundo O’brien (2004), os sistemas colaborativos podem aumentar a comunicação e a colaboração necessárias para aumentar drasticamente os serviços de coordenação e apoio administrativos na cadeia de valor de uma empresa. Os sistemas de informações assumem diversas categorias, e são classificados conforme a característica de seus usuários.

Vale destacar aspcetos relativos a sistemas especialialistas (best-of-breed), em comparação com sistemas integrados de gestao empresarial, denominados de SIGE ou ERP. Padoveze (2009) comenta as vantagens e desvantagens do SIGE e do Best-Of-Breed:

a) as vantagens do Sige: única solução de vendas, viabilidade, proposta abrangente e desvantagem: tempo de implantação e diversidade;

b) as vantagens do Best-of-breed: especialização, tempo, escolha e desvantagem: consolidação potencial e opções de interfaceamento.

Podemos ter um sistema específico para gerencial a distribuição de produtos acabados, bem como podemos ter um sistema que congregue toda a cadeia logística e de transporte. Alguns sistemas são construídos na base da cadeia e suprimentos (suply chain), outros são concebidos na base de distribuição, e outros são concebidos na base de todos os transportes, tanto de mercadorias internadas quanto de mercadorias remetidas (PADOVEZE, 2009, pag. 97).

Segundo Sordi (2003), os sistemas se classificam em:

a) legados: para classificar sistemas mais antigos;

b) integrados: com base de dados única, compartilhando informações entre as diversas aplicações, exemplo ERP e sistemas colaborativos: envolvendo usuários internos e externos, adotando a Internet como plataforma principal para as operações da empresa.

Todo avanço tecnológico e a viabilização de ferramentas de TIC só foram possíveis com a 
Internet, criada em 1969, pelos EUA, para fins militares:

A Internet é a rede mundial de computadores conectados, usando um padrão de protocolo de tal forma que qualquer computador na rede possa enviar e receber mensagem de qualquer outro computador. Em 1993, a Internet foi aberta aos negócios, com as vantagens de fácil publicação de informações, custo reduzido e facilidade de uso, e a desvantagem de risco a curto prazo. A World Wide Web foi criada em 1990, e o navegador, em 1993 (GOMES, 2004, p. 165).

Todavia, apesar do desenvolvimento deste sistemas e a disponibilidade proporcionada pela internet, a TI, na SCM ainda não é explorada em todo o seu potencial. Como a evolução dos códigos abertos de informação a integração de dados, por meio da internet, entre as empresas integrantes de uma SCM poderá se desenvolver para um ambiente padronizado e integrado, para fins de gestão empresarial de toda a cadeia produtiva.

\subsection{Tecnologia e sistema de informação e comunicação na logística}

Segundo Gomes (2004), a tecnologia e os SI - sistema de informações são o elos entre as atividades da empresa, e permitem a interação com a logística, os hardwares de TI para se resumem: microcomputadores, palmtops, código de barras, coletores de dados, radiofreqüência, transelevadores, sistemas de GPS, computadores de bordo e picking automático.

E as aplicações de softwares, segundo Gomes (2004), são normalmente: roteirizadores, WMS, GIS, DRP, MRP, simuladores, otimizadores de rede, previsões de vendas e EDI.

Dentre as perspectivas para soluções SCM, destaca-se o SRM:

A solução de SCM tem apresentado uma evolução constante; o web-based SCM e o CPFR são dois exemplos de um conjunto amplo de melhorias e inovações ocorridas ao longo das últimas décadas. Dentro desta linha evolutiva, há diversas tendências e aspectos do SCM que estão sendo trabalhados e aprimorados. Um destes aspectos que merece ser destacado é a iniciativa de Supplier Relationship Management (SRM). A proposta básica do SRM é análoga ao tratamento que a solução CRM dá aos clientes da empresa, só que voltada à cadeia de fornecedores (SORDI, 2003, p. 70).

Entre as práticas de SCM, as principais que se relacionam com a tecnologia da informação, segundo Pires (2010): EDI (Electronic Data Interchange), ECR (Efficient Consumer Response), VMI (Vendor Managed Inventory), CR (Contínuos Replenishment), E-procurement e ferramenta de planejamento colaborativo CPFR (Collaborative Planning, Forecasting, and Replenishment), sendo uma forma de trabalho conjunto em toda a cadeia, ajudando a gerenciar processos conjuntamente e compartilhamento de informações.

Pires (2010) ressalta a importância da confiança mútua entre os parceiros integrantes de uma SCM, para viabilidade destas práticas gerenciais relacionadas a tecnologia da informação.No entanto apesar da destacada importância na SCM, a grande dificuldade está na medição desse desempenho: 
[...] a Gestão da Cadeia de Suprimentos (Supply Chain Management -SCM) tem emergido, nos últimos anos, como uma nova e promissora fronteira na busca de vantagens competitivas, pelas empresas industriais. Dentre as inúmeras questões envolvidas na SCM, uma que merece especial atenção é a determinação de indicadores de desempenho adequados e confiáveis, ou seja, indicadores que mostrem, efetivamente, se as empresas estão caminhando no sentido de suas metas e no atendimento das expectativas de seus clientes (ARAVECHIA, 2001, p. 15).

A concorrência atual entre as empresas alcança a totalidade da cadeia de suprimentos; portanto as disputas são entre cadeias, e, dessa forma, é fundamental o monitoramento dessas informações. Torna-se relevante o desenvolvimento de indicadores de desempenho para monitoramento dos processos e alcançar a eficácia da gestão empresarial em toda a SCM.

\section{Tecnologia da informação e comunicação na SCM como estratégia competitiva}

\subsection{Lacuna identificada na literatura}

Apesar da comprovada importância da TIC na SCM, várias pesquisas apontam a falta de conhecimento dos gestores nesta área de informática. Grandes somas de recursos são direcionadas para investimentos em equipamentos e programas de computador, sem, entretanto, uma real análise das necessidades da empresa ou de sua cadeia produtiva.

A maioria dos indicadores existentes para análise do desempenho da SCM é voltada para mensuração financeira, deixando para a análise empírica a identificação das reais necessidades e avaliações qualitativas na aplicação prática destes conceitos nas empresas.

$\mathrm{Na}$ implementação da estratégia da empresa há consenso que a TIC é fator preponderante no processo de gesão empresarial. Dado a importância do tema, ainda é pouco o que se discute sobre a vantagem competitiva, e que poderia ser conseguida com a utilização da TIC, se melhor explorada, para troca de informações entre os parceiros da cadeia de suprimentos em que a empresa efetivamente participa.

\subsection{Objetivo}

O objetivo deste trabalho é evidenciar da importância da TIC na gestão da cadeia de suprimentos, para que o gestor da cadeia possa identificar e explorar possíveis vantagens, através da integração entre os parceiros desta cadeia, na troca de informações e dados estratégicos, e se torne um diferencial competitivo para toda a cadeia de suprimentos.

\subsection{Contribuição estratégica da TIC na SCM}

Conforme explorado na revisão bibliográfica a gestão da cadeia de suprimentos (supply chain management) é mais bem aproveitada em todo seu potencial por grandes grupos econômicos. Pequenas e médias empresas, apesar de representarem grande maioria das empresas no Brasil, geralmente estão distantes dessa ferramenta de gestão colaborativa. 
Pela análise do comportamento de grandes organizações, por meio da literatura publicada sobre este tema, verifica-se que muitas têm ainda dificuldades na implementação de seus ERP, não integrando por completo seus processos, utilizando-se ainda de software legados (antigos).

Apesar da tendência identificada na revisão na literatura, sobre linguagens universais como XBRL e XML, ainda muitos sistemas usam linguagem e métodos exclusivos, o que dificulta a troca de informações entre as empresa na cadeia de suprimentos.

Quando se analisa o comportamento do governo através do Ministério da Fazenda, instituiu o SPED - sistema público de escrituração digital, com destaque para a NFe - Nota Fiscal Eletrônica, com fins de combate a sonegação e aumento da formalidade das empresas e conseqüente aumento na arrecadação de impostos, notam-se os primeiros passos para a popularização da meios de comunicação de códigos abertos e universais entre as empresas de forma geral.

Esta exigência do governo imposta por meios legais a todas as empresas, de todos os portes, abrange desde grandes corporações até micro e pequenas empresas. Com isso o governo deu um grande passo e salto de qualidade na gestão da informação de todas as empresas, que deverão adequar seus sistemas em um padrão fiscal e contábil em nível nacional, por meio de uma linguagem aberta e universal.

Dessa forma as empresas integrantes de importantes cadeias de suprimentos deverão adequar seus software e controles internos ao padrão proposto pelo governo federal, e poderão incorporar nessa cadeia empresas de menor porte, pois estarão utilizando uma linguagem universal e emitindo documentos padronizados e aptos a emitir e receber informações em meios eletrônicos, em tempo real.

Essas empresas poderão fazer uso dessa obrigação e transformar isto em vantagem competitiva, mediante a troca de informações fiscais, e agregar outras de interesse estratégico, para compartilhar deste novo ambiente virtual fundamentado em documentos digitais e escrituração eletrônica.

Neste contexto, as empresas líderes de suas cadeias de suprimentos devem preparar um inventário das informações estratégicas, necessárias para uma real vantagem competitiva e incorporar nas informações fiscais obrigatórias. Assim, elas devem definir padrões e medidas de desempenho para a cadeia de suprimentos, e reforçar as parcerias entre clientes e fornecedores.

A SCM sugere a busca de parcerias na gestão colaborativa da cadeia, e visa à maximização do resultado ao longo de toda a cadeia produtiva e de distribuição, desde o produtor até o consumidor final do produto, na outra extremidade da cadeia de suprimentos.

As empresas devem também promover a integração de dados entre os membros da cadeia, para gerar relatórios de suporte a tomada de decisão, parametrizar os sistemas para que possam trocar informações em tempo real, e de forma mais automatizadas, evitando erros de entrada de 
dados, e gerando ações automáticas de interesse entre os membros da cadeia.

\subsection{Metodologia}

A abordagem metodológica utilizada neste documento é analítico-conceitual e o artifício empregado na sua construção e organização calca-se em pesquisa bibliográfica (síntese da literatura existente), num caráter preponderantemente qualitativo, com análise crítica dos problemas levantados e sua discussão, conforme a metodologia apontada por Acevedo (2009).

\section{Conclusão}

Muito se evoluiu desde o desenvolvimento de soluções pontuais na área da tecnologia da informação e comunicação: telefones, computadores e processadores, programas de computador, passando para fibras óticas e comunicação sem fio.

Com a evolução dos micro-computadores, da capacidade de processamento e da capacidade de armazenamento de dados, os algoritmos sofisticados nos sistemas de informações, a qualidade na comunicação e, sobretudo pela contribuição da internet para a integração de empresas e pessoas, houve um salto de qualidade potencial nas informações geradas e armazenadas pelas as empresas.

Neste ambiente de competição acirrada e globalizada, a necessidade de transformar a informação em conhecimento passa a ser fator de estratégia competitiva, e muitas ferramentas de gestão da SCM foram privilegiadas com essa revolução tecnológica, tornando possível a troca de informação em tempo real.

Recentemente passou a existtir uma imposição legal do governo brasileiro para que todas as empresas façam a substituição de documentos fiscais, conhecidos como Nota Fiscal (NF), emitidos em meio impresso sejam substituídos por Notas Fiscais Eletrônicas (NF-e). Atualmente todas as empresas com atividade de indústria e atacado de quaisquer produtos são obrigadas ao uso da NF-e. Em outras palavras, a partir desta exigência legal, todas as empresas estarão obrigadas ao uso da tecnologia de informação e comunicação para gerar informações, com capacidade de importar, armazenar e exportar informações quantitativas e qualitativas para todos os membros da cadeia de suprimentos. A tecnologia XBRL permitirá a troca de informações contábeis entre membros da cadeia de suprimentos localizados em outros países.

A popularização da nova linguagem de comunicações imposta pelo governo brasileiro para fins de fiscalização e arrecadação poderá ser o passo essencial para a padronização de dados e informações geradas pelas as empresas, inclusive micro e pequenas empresas, que poderão ter sua inclusão em grandes cadeias de suprimentos, por adequação na geração de documentos e informações de forma padronizada.

Por meio da linguagem e códigos universais de utilização livreas empresas, 
independentemente de seu porte, poderão trocar informações estratégicas de negócios em um ambiente de gestão integrada e colaborativas entre os pares. Com isso, grandes corporações que já utilizam sistemas integrados de gestão poderão se interagir com os demais elos da cadeia de suprimentos, incluindo aqueles relacionados com pequenas e médias empresas. A SCM poderá se expandir e permitir em alguns casos a participação de pequenos negócios em sua cadeia, porque um grande fator limitativo relacionado a capacidade de troca de informações foi rompido.

Portanto não se justificam os comportamentos de alguns gestores que subutilizam a tecnologia da informaçãoe comunicação, seja na adoção de modelos tradicionais e arcaicos exigidos para atendimento a modelos legais, seja pela falta de visão holística na gestão integrada de processos. Por meio da disponilibilização da informação de forma ampla, as empresas poderão de interagir na troca de informações estratégicas em tempo real.

Finalmente, tendo em vista que esta pesquisa trata-se de um ensaio teórico, sugerem-se futuras pesquisas empíricas para verificação da utilização de tecnologia da informação e comunicação e tentar para mensurar sua contribuição efetiva no apoio às estratégias competitivas na gestão de cadeia de suprimentos.

\begin{abstract}
The competition among companies is increasing significantly and according to the experts the current competition is running among supply chains, instead of isolated companies. The information in the enterprise environment has evolved significantly in the last few decades, by means of the contribution of the information and communication technology (ICT), that presents constants innovations throughout the time However so that the competitive advantage should be reached, it is fundamental that the chains' partners exchange adequately strategic information for managing knowledge and operations status. To attend this requirement, the support of the information and communication technology (ICT) is essential. This article discuss this subject by a theoretical essay. The used methodology wass analytical-conceptual, therefore theoretician, with exploratory objective. The methodology used in its construction and organization was bibliographical, that is, making synthesis of existing literature, in a preponderantly qualitative character.
\end{abstract}

Key-words: information and communication technology; supply chain management; competitive strategy.

\title{
Referências
}

ACEVEDO, Cláudia Rosa; NOHARA, Jouliana Jordan. Monografia no curso de administração. Guia completo de conteúdo e forma. $3^{a}$. Ed. São Paulo: Atlas, 2009.

ANGELONI, Maria Terezinha (org.). Estratégias: formulação implementação e avaliação. São Paulo: Ed. Saraiva, 2008.

ARAVECHIA, C.H. M. Avaliação de desempenho de cadeia de suprimento. 2001.114 f. Dissertação (Mestrado) Programa de Pós Graduação em Engenharia de Produção, Universidades Metodista de Piracicaba, Piracicaba, 2001.

CARVALHO, L. Nelson; LEMES, Sireli. Contabilidade internacional para graduação. São Paulo: Atlas, 2010.

FLEURY, Paulo Fernando; WANKE; Peter; FIGUEIREDO; Kleber Fossati. (org.). Logística Empresarial - a perspectiva brasileira. São Paulo: Atlas, 2000. 
GOMES, Carlos Francisco Simões; RIBEIRO, Priscilla Cristina Cabral. Gestão da cadeia de suprimentos - integrada a tecnologia da informação. São Paulo: Pioneira Thomson Learning, 2004.

LEME FILHO, Trajano. Business intelligence no Microsoft Excel. Rio de Janeiro: Axcel Brooks, 2004.

MAÇADA, Antonio Carlos Gastaud; FELDENS, Luis Felipe; SANTOS, André Moraes dos. Impacto da tecnologia da informação na gestão das cadeias de suprimentos - um estudo de casos múltiplos. Revista Produção, São Carlos, v. 14, n.1, p. 1-12, jan.-abr. 2007.

MINISTÉRIO DA FAZENDA. Portal da nota fiscal eletrônica. Disponível em: <www.nfe.fazenda.gov.br/portal >. Acesso em: 07 set. 2010.

O’BRIEN, James A. Tradução: MOREIRA, Célio Knipel; et al. Sistemas de informações - e as decisões gerenciais na era da internet. $2^{\text {a }}$. Ed. São Paulo: Saraiva, 2004.

OLIVEIRA, Djalma de Pinho Rebouças de. Sistemas de informações gerenciais - estratégicas táticas e operacionais. $13^{\mathrm{a}}$. Ed. São Paul: Ed. Atlas, 2010.

OLIVEIRA, Jayr Figueiredo de. Sistemas de informação - um enfoque gerencial inserido no contexto empresarial e tecnológico. 2a. Ed. Érica, 2000.

PADOVEZE, Clóvis Luís. Sistemas de informações contábeis. Fundamentos e análise. 6ª . Ed. São Paulo: Atlas, 2009. Clóvis Luís. Introdução à contabilidade - com abordagens para não-contadores. São Paulo: Pioneira Thomson Learning, 2006.

PIRES, Silvio R. I. Gestão da cadeia de suprimentos. (SUPPLY CHAIN MANAGEMENT). 2a . Ed. São Paulo: Atlas, 2010 .

SORDI, José Osvaldo de. Tecnologia da informação aplicada aos negócios. São Paulo: Atlas, 2003.

\section{Dados dos autores:}

Nome completo: Adilson Torres

Filiação institucional: Universidade Metodista de Piracicaba - UNIMEP

Departamento: PPGA - Programa de Pós-Graduação em Administração

Função ou cargo ocupado: Mestre em Administração

Endereço completo para correspondência (bairro, cidade, estado, país e CEP): R. Agenor Alves

Araújo, 45, Centro, Guaxupé - MG, Brasil, CEP 37.800-000.

Telefones para contato: (35) 35511705

E-mail: adilson_torres@oi.com.br

Nome completo: Clóvis Luís Padoveze

Filiação institucional: Universidade Metodista de Piracicaba - UNIMEP

Departamento: PPGA - Programa de Pós-Graduação em Administração

Função ou cargo ocupado: Professor Doutor Titular (Controladoria e Contabilidade)

Endereço completo para correspondência (bairro, cidade, estado, país e CEP): Rua Fioravante Luis

Angolini, 51 - Residencial Furlan ,13451 208 - Santa Bárbara dOeste-SP.

Telefones para contato: (019) 34541984

e-mail: cpadoveze@yahoo.com.br 
Nome completo: Silvio Roberto Ignácio Pires

Filiação institucional: Universidade Metodista de Piracicaba - UNIMEP

Departamento: PPGA - Programa de Pós-Graduação em Administração

Função ou cargo ocupado: Professor Doutor Titular.

Endereço completo para correspondência (bairro, cidade, estado, país e CEP): Rodovia do Açúcar, Km 156, Piracicaba, SP, 13400-911.

Telefones para contato: $19-31241560$

E-mail: sripires@unimep.br

Enviado em: 03/03/2011

Aprovado em: 15/03/2012 